\title{
Development and Validation of Chronopotentiometric Method for Imidacloprid Determination in Pesticide Formulations and River Water Samples
}

\author{
Ana Đurović, ${ }^{1}$ Zorica Stojanović, ${ }^{1}$ Snežana Kravić, ${ }^{1}$ Nada Grahovac, \\ Vojislava Bursić, ${ }^{3}$ Gorica Vuković, ${ }^{4}$ and Zvonimir Suturović ${ }^{1}$ \\ ${ }^{1}$ Faculty of Technology, Department of Applied and Engineering Chemistry, University of Novi Sad, \\ Bulevar Cara Lazara 1, 21000 Novi Sad, Serbia \\ ${ }^{2}$ Institute of Field and Vegetable Crops, Maksima Gorkog 30, 21000 Novi Sad, Serbia \\ ${ }^{3}$ Faculty of Agriculture, University of Novi Sad, Trg Dositeja Obradovića 8, 21000 Novi Sad, Serbia \\ ${ }^{4}$ Institute of Public Health, Bulevar Despota Stefana 54a, 11000 Belgrade, Serbia
}

Correspondence should be addressed to Zorica Stojanović; zorica.stojanovic@uns.ac.rs

Received 15 December 2015; Accepted 31 January 2016

Academic Editor: Josep Esteve-Romero

Copyright (C) 2016 Ana Đurović et al. This is an open access article distributed under the Creative Commons Attribution License, which permits unrestricted use, distribution, and reproduction in any medium, provided the original work is properly cited.

\begin{abstract}
A new electrochemical method for determination of imidacloprid using chronopotentiometry on thin film mercury and glassy carbon electrode was presented. The most important experimental parameters of chronopotentiometry were examined and optimized with respect to imidacloprid analytical signal. Imidacloprid provided well-defined reduction peak in Britton-Robinson buffer on thin film mercury electrode at $-1.0 \mathrm{~V}$ (versus $\mathrm{Ag} / \mathrm{AgCl}(\mathrm{KCl}, 3.5 \mathrm{~mol} / \mathrm{L})$ ) and on glassy carbon electrode at $-1.2 \mathrm{~V}$ (versus $\mathrm{Ag} / \mathrm{AgCl}(\mathrm{KCl}, 3.5 \mathrm{~mol} / \mathrm{L}))$. The reduction time was linearly proportional to concentrations from 0.8 to $30.0 \mathrm{mg} / \mathrm{L}$ on thin film mercury electrode and from 7.0 to $70.0 \mathrm{mg} / \mathrm{L}$ on glassy carbon electrode. The detection limits were $0.17 \mathrm{mg} / \mathrm{L}$ and $0.93 \mathrm{mg} / \mathrm{L}$ for thin film mercury and glassy carbon electrode, respectively. The estimation of method precision as a function of repeatability and reproducibility showed relative standard deviations values lower than 3.73\%. Recovery values from 97.3 to $98.1 \%$ confirmed the accuracy of the proposed method, while the constancy of the transition time with deliberated small changes in the experimental parameters indicated a very good robustness. A minor influence of possible interfering compounds proved good selectivity of the method. Developed method was applied for imidacloprid determination in commercial pesticide formulations and river water samples.
\end{abstract}

\section{Introduction}

In the past several decades, due to the progress in worldwide agricultural production, use of pesticides has been significantly increased. Increased public concern about the dietary risks of pesticides led to a major change in pesticide law. As a result, current pesticide policy in Europe and America is focused on reducing pesticide applications $[1,2]$. Nevertheless, some of these chemicals are very persistent, which led to their growing presence in the environment (crops, soil, and water). Thereby, analytical methods concerned with pesticide levels in environmental samples have attracted significant attention.
Imidacloprid [1-6(Chloro-3-pyridylmethyl)-N-nitroimidazolidin-2-ylideneamine] (Figure 1) is the most commonly used member of neonicotinoid group of insecticides developed in the early 1990s. Since its discovery and utilization, it became the most widely used insecticide for pest control on a broad range of crops [3]. As agonist of the postsynaptic nicotinic acetylcholine receptors, imidacloprid selectively acts on the insect's central nervous system, with much lower toxicity to mammals $[4,5]$. Still, numerous concerns exist about its use. Recent studies indicated that widespread agricultural use of imidacloprid and other neonicotinoids may be contributing to decline of honey bee and bumble bee colonies [6-9]. In addition, extreme sensitivity of many aquatic species [10-15] 


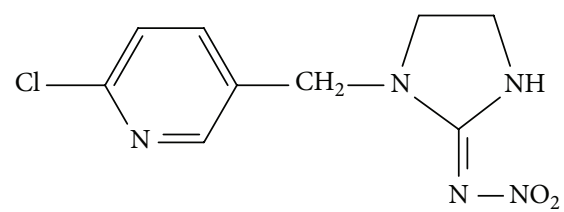

FIGURE 1: Structural formula of imidacloprid.

and birds [16] towards imidacloprid was noticed. Moreover, its chemical properties such as high water solubility and long half-life in soil and water, in the absence of light, contribute to its environmental persistence and susceptibility to transport into aquatic ecosystems through runoff and drainage of agricultural areas [10, 17]. Thus, increased concentrations of this insecticide in environmental water samples were detected in many countries worldwide [18-24] with highest reported concentration of $0.32 \mathrm{mg} / \mathrm{L}$ in Netherlands [25]. However, lacking systematic environmental monitoring in most countries, due to expensive and time-consuming analytical methods for pesticide analysis, these data are incomplete. Consequently, development of rapid and low cost methods for pesticide analysis of environmental water samples is of crucial importance.

Techniques based on liquid chromatography have been mostly applied for imidacloprid determination in water samples [15, 20, 26-29]. Nowadays, liquid chromatography with mass spectrometry detection represents the most selective and sensitive technique, allowing the identification of pesticide residues at very low levels. However, the high price of HPLC-MS instrumentations still presents an obstacle for its wide use, especially in developing countries. Recently reported data showed that liquid chromatography with UV detection [30] and ELISA [31] could be used as cheaper and still valid analytical procedures for pesticide determination. Even though these techniques are routine in pesticide determination, bulky nonportable instrumentation, long analysis time, and complicated sample preparation make them unsuitable for in-field analysis.

In the past few decades, electrochemical methods have received increasing attention for pesticide determination, due to their speed, simplicity, sensitivity, and more feasible analysis [32]. Numerous studies about electrochemical determination of imidacloprid based on its reduction have been reported. Imidacloprid reduces in two steps, by capturing four electrons in the first step and two in the second and producing the hydroxylamine and amine derivatives, respectively [33]. Differential pulse polarography [33] and square wave adsorptive stripping voltammetry [34] using hanging mercury drop electrode (HMDE) were among first electrochemical approaches applied for imidacloprid determination in commercial formulations and river water samples. Recently, the use of voltammetry on glassy carbon electrode (GCE) [35], carbon paste electrode (CPE) [36, 37], bismuth film electrode (BiFE) [38], and silver-amalgam film electrode ( $\mathrm{Hg}(\mathrm{Ag}) \mathrm{FE})$ [39] was described. In order to increase sensitivity and selectivity in the imidacloprid determination, different modification procedures of usual electrodes were applied. These modified electrodes include Prussian blue multiwalled carbon nanotubes modified GCE (Prussian blue/MWNT/GCE) [40], poly(carbazole)/chemically reduced graphene oxide modified GCE (PCz/CRGO/GCE) [32], nanosilver Nafion $\% /$ nano$\mathrm{TiO}_{2}$ Nafion modified GCE $\left(\mathrm{nAgn}_{\mathrm{f}} / \mathrm{nTiO}_{2} \mathrm{n}_{\mathrm{f}} / \mathrm{GCE}\right)$ [41], $\beta$-cyclodextrin polymer functionalized reduced-graphene oxide modified GCE ( $\beta$-CDP/rGO/GCE) [42], imprinted poly(o-phenylenediamine) membranes at reduced graphene oxide modified electrode (Imprinted PoPD-RGO/GCE) [43], and copper(II) phthalocyanine modified carbon ceramic electrode (CuPc/GCE) [44]. Application of modified electrodes, unlike bare GCEs, although having a lower detection limit, mainly involves long and complicated preparation procedures, leading to greatly prolonging the analyses.

A detailed literature review [32-44] indicated that application of chronopotentiometry in imidacloprid determination has not been reported until now. Thereby, this study is concerned with utility of chronopotentiometry with use of thin film mercury electrode (TFME) as a working electrode for quantification of imidacloprid content in pesticide formulations and river water samples. The proposed method was validated in terms of linearity, LOD, LOQ, precision (repeatability and repeatability), selectivity, accuracy, and robustness according to US EPA guidelines [45]. Additionally, chronopotentiometry with GCE was applied for imidacloprid determination as well and was used for comparison purposes. Unlike modified GCEs that have been mostly implied for imidacloprid determination, electrodes applied in this study do not require complicated preparation procedures.

\section{Experimental}

2.1. Chemicals and Reagents. Imidacloprid analytical standard (>99.1\%) was purchased from Dr. Ehrenstorfer, Augsburg, Germany. Standard stock solution of imidacloprid $(0.40 \mathrm{~g} / \mathrm{L})$ was prepared by dissolution of solid standard in distilled water. The solution was stable for a period of three weeks if stored in the dark at $4^{\circ} \mathrm{C}$. Orthophosphoric, boric, and acetic acids of analytical grade were provided by Lach-Ner (Brno, Czech Republic). HPLC grade methanol and analytical grade hydrochloric acid, sulphuric acid, and sodium sulphite were purchased from Merck (Darmstadt, Germany). Sodium hydroxide was of analytical grade (Donau Chemie, Wien, Austria). Studied supporting electrolytes were citrate buffer, phosphate buffer, Britton-Robinson (BR) buffer, acetate buffer, hydrochloric acid, sulphuric acid, and sodium sulphite solutions. BR buffer was prepared from equimolar $0.04 \mathrm{~mol} / \mathrm{L}$ stock solutions of orthophosphoric, boric, and acetic acids. Required $\mathrm{pH}$ value of the BR buffer was adjusted by addition of $0.20 \mathrm{~mol} / \mathrm{L}$ sodium hydroxide solution. All other chemicals used for the experiments were of analytical grade (Merck, Darmstadt, Germany) and were used without further purification. Distilled water obtained from a MonoDest 3000E system (Brand, Wertheim, Germany) was used throughout the experiments.

2.2. Instrumentation. Instrumentation for chronopotentiometry consisted of automatic stripping analyser (M1 analyser) of domestic construction [46]. The analyser was coupled 
to an Epson LQ-570 printer (Suwa, Nagano, Japan). The electrochemical cell consisted of glass vessel with tapered bottom volume of $50 \mathrm{~mL}$, three-electrode system, and electrical stick stirrer. Glassy carbon disc electrode (total surface area of $7.07 \mathrm{~mm}^{2}$ ) was used as a working electrode, but also as an inert support for TFME. A platinum wire (diameter = $0.7 \mathrm{~mm}$, length $=7 \mathrm{~mm}$ ) was used as a counter electrode, while the reference was $\mathrm{Ag} / \mathrm{AgCl}(\mathrm{KCl}, 3.50 \mathrm{~mol} / \mathrm{L})$ electrode. All values of the potential were shown versus $\mathrm{Ag} / \mathrm{AgCl}(\mathrm{KCl}$, $3.5 \mathrm{~mol} / \mathrm{L}$ ) reference electrode. A digital $\mathrm{pH}$ meter model MA 5705 (Iskra, Kranj, Slovenia) with combined glass electrode was used for all pH measurements. An ultrasonic bath (Iskra, Kranj, Slovenia) with working frequency of $30 \mathrm{~Hz}$ and power of $500 \mathrm{~W}$ was used after the polishing procedure.

\subsection{Preparation and Maintenance of the Working Electrodes}

2.3.1. Glassy Carbon Electrode. After each finished set of experiments the surface of the GCE was cleaned with filter paper wetted firstly with acetone and then with distilled water. For maintenance of the good quality of the glassy carbon surface, whenever the sensitivity dropped off, or after prolonged disuse of GCE, the polishing procedure was performed using aluminium oxide slurry, gained by mixing aluminium oxide (grain size $0.5 \mu \mathrm{m}$, Merck, Darmstadt, Germany) with distilled water, on a special cotton panel, until a mirrorlike surface was obtained. For removing residual particles, the electrode was first wiped with filter paper wetted with acetone and then with distilled water, and hereupon it was sonicated in a mixture of distilled water and ethanol $(1: 1, \mathrm{v} / \mathrm{v})$ for 10 minutes. Afterwards, electrochemical pretreatment was performed by chronopotentiometric cycling between $-0.70 \mathrm{~V}$ and $0.70 \mathrm{~V}$ (10 cycles) applying the current of $7.0 \mu \mathrm{A}$, in $0.01 \mathrm{~mol} / \mathrm{L}$ sulphuric acid. The unmodified GCE prepared this way was used as an inert support for TFME and as bare GCE for comparison purposes.

2.3.2. Thin Film Mercury Electrode. Deposition of the thin mercury film was performed potentiostatically at the potential of $-0.40 \mathrm{~V}$ for $4 \mathrm{~min}$, from the solution containing $0.02 \mathrm{~mol} / \mathrm{L}$ hydrochloric acid and $0.10 \mathrm{~g} / \mathrm{L}$ of $\mathrm{Hg}^{2+}$ ion. The working electrode could be used for approximately 50 analyses, after which the film was removed, and deposition was repeated by the same procedure.

\subsection{Samples and Sample Preparation}

2.4.1. Pesticide Formulations. Pesticide formulations of imidacloprid: Confidor 200 SL (Bayer CropScience, Monheim, Germany), Confidor 70 WG (Bayer CropScience, Monheim, Germany), Prestige 290 FS (Bayer CropScience, Monheim, Germany), Gat Go 20 OD (GAT Microencapsulation AG, Ebenfurth, Austria), Imidor 70 WS (Stockton Chemical, Florida, USA), and Kohinor 200 SL (Celsius Property, Amsterdam, Netherlands) were purchased from the local agricultural supplier (Novi Sad, Serbia). Due to high concentration of imidacloprid in the commercial formulations, appropriate dilution was required to obtain a suitable range of concentrations for chronopotentiometric analysis. The proper volume or weight of each sample was transferred to a $250 \mathrm{~mL}$ calibrated flask and filled with distilled water to accomplish around $0.5 \mathrm{~g} / \mathrm{L}$ of imidacloprid. For chronopotentiometric analysis the appropriate volume of this solution was transferred to the electrochemical cell so that the final concentration of imidacloprid was in the range from $2 \mathrm{mg} / \mathrm{L}$ to $20 \mathrm{mg} / \mathrm{L}$.

2.4.2. River Water Samples. River water samples were collected in plastic bottles from the River Danube at five different locations on the territory of Novi Sad (Serbia) and were stored in the dark at $4^{\circ} \mathrm{C}$ until the analysis. Samples were taken in the urban recreational zone at the following sites: Petrovaradin fortress (1254 km of the flow), "Štrand" beach (1257 km of the flow), fishing weekend resort (1258 km of the flow), weekend resort "Kamenjar" (1263 km of the flow), and beach "Mačkov Prud" (1266 km of the flow).

A volume of $250 \mathrm{~mL}$ of each sample was filtered through membrane syringe filter with pore diameter of $0.45 \mu \mathrm{m}$ (Chromafil ${ }^{\oplus}$ Xtra PET-45/25, Macherey-Nagel, Düren, Germany). For performing chronopotentiometric analysis, $5 \mathrm{~mL}$ of water sample was added to the electrochemical cell filled with $15 \mathrm{~mL}$ of supporting electrolyte and analysed according to the previously optimized conditions. Filtered water samples were spiked with imidacloprid standard solution, and the final imidacloprid concentration in spiked water samples was $1 \mathrm{mg} / \mathrm{L}$.

For performing LC-MS/MS analysis [47], extraction and preconcentration of previously filtered river water samples were performed by solid-phase extraction (SPE) method with Supelco, Supel ${ }^{\mathrm{Tw}}$-Select HLB cartridges $(200 \mathrm{mg}, 6 \mathrm{~mL})$, preconditioned with $5 \mathrm{~mL}$ of methanol and $5 \mathrm{~mL}$ of distilled water. Blank or spiked water samples $(250 \mathrm{~mL})$ were loaded on the cartridges at the rate of $3-5 \mathrm{~mL} / \mathrm{min}$ by using water vacuum pump. After passing the sample, the cartridges were washed with $10 \mathrm{~mL}$ of distilled water and air dried for 10 minutes, and the analyte was eluted with $5 \mathrm{~mL}$ of methanol. The eluate was brought to dryness under a gentle nitrogen stream. The residue was dissolved in the $0.25 \mathrm{~mL}$ of initial mobile phase, and $10 \mu \mathrm{L}$ was injected into LC-MS/MS system. Quantification of imidacloprid was performed by means of the calibration curve method.

2.5. Chronopotentiometric Measurement. Electrochemical cell filled with $20 \mathrm{~mL}$ of the analysed solution was used for performing chronopotentiometric measurements. Dissolved oxygen was removed from the solution by adding previously optimized concentration of the saturated solution of sodium sulphite [48] and stirring the solution for $30 \mathrm{~s}$ and $15 \mathrm{~s}$ in each successive cycle. After the deaeration period, in order to enable diffusive mass transfer in the vicinity of the working electrode, the solution was left to rest for $10 \mathrm{~s}$, and the analytical step was performed by recording of chronopotentiogram in the appropriate negative potential window. All experiments were performed using five replicates at the ambient temperature $\left(23-25^{\circ} \mathrm{C}\right)$. 
2.6. Optimization and Validation Procedures. In order to achieve the optimum conditions for chronopotentiometric determination of imidacloprid, the influence of the most important experimental parameters on imidacloprid analytical signal, including type and $\mathrm{pH}$ of the supporting electrolyte, initial potential, and reduction current were studied. The experimental parameter that provided the highest, well defined, reproducible, and sharp analytical signal of the analyte was accepted as optimal. The method was validated with respect to linearity, limit of detection (LOD), limit of quantification (LOQ), precision, selectivity, accuracy, and robustness according to US EPA guidelines [45]. Applicability and practical usage of the proposed method were verified by analysing real river water samples as well as pesticide formulations containing imidacloprid.

2.7. LC-MS/MS Analysis. In order to check the accuracy of the proposed chronopotentiometric method, LC-MS/MS method was also used to quantify imidacloprid content in river water samples extracted as described in Section 2.4.2. Chromatographic analysis was performed using an Agilent 1200 Series liquid chromatograph (Agilent Technologies Inc., Santa Clara, CA, USA) equipped with triple quad mass spectrometer Agilent 6410 (Agilent Technologies Inc., Santa Clara, CA, USA). Separation was achieved using XBridge C18 column $(150 \times 3 \mathrm{~mm})$ with $3.5 \mu \mathrm{m}$ particle size (Waters, Milford, USA) maintained at $40^{\circ} \mathrm{C}$. The mobile phase consisted of $0.1 \%(\mathrm{v} / \mathrm{v})$ formic acid in methanol (A) and $0.1 \%$ $(\mathrm{v} / \mathrm{v})$ formic acid in water (B), with a flow rate of $0.5 \mathrm{~mL} / \mathrm{min}$. The gradient used started with $70 \%$ of mobile phase B during 2-minute hold constant, followed by a linear gradient reaching $50 \% \mathrm{~B}$ after 15 minutes, kept constant for 4 minutes, and finally decreased to $30 \%$ B after 20 minutes and kept on $30 \%$ for 6 minutes. Mass spectrometer was operated in multiple reactions monitoring mode for mass analysis of positive ions generated by electrospray ionization. The operating parameters for the mass spectrometer were as follows: heater gas temperature of $350^{\circ} \mathrm{C}$ and vaporization temperature of $250^{\circ} \mathrm{C}$. Nitrogen was used as a nebulizer gas at $50 \mathrm{psi}$ and flow rate of $5 \mathrm{~L} / \mathrm{min}$, capillary voltage of $3500 \mathrm{~V}$, and charging voltage of $2000 \mathrm{~V}$. For quantification of imidacloprid two precursor-to-product ion transitions were chosen 256.0208.7 and 256.0-174.6. MassHunter Workstation software (Agilent Technologies, Santa Clara, CA, USA) was used for the control of equipment, data acquisition, and analysis.

\section{Results and Discussion}

3.1. Influence of the Type and $p H$ of the Supporting Electrolyte. The selection of a suitable supporting electrolyte is considered as an essential step in electrochemical studies because its composition and $\mathrm{pH}$ can significantly affect ongoing electrochemical reactions [49]. The dependence of chronopotentiometric signals of imidacloprid on the type of the supporting electrolyte was evaluated using BR buffer, $0.10 \mathrm{~mol} / \mathrm{L}$ citrate buffer, $0.10 \mathrm{~mol} / \mathrm{L}$ phosphate buffer, $0.01 \mathrm{~mol} / \mathrm{L}$ hydrochloric acid, $0.01 \mathrm{~mol} / \mathrm{L}$ sulphuric acid, and $4.50 \mathrm{~g} / \mathrm{L}$ sodium sulphite. In all studied electrolytes imidacloprid exhibited a single

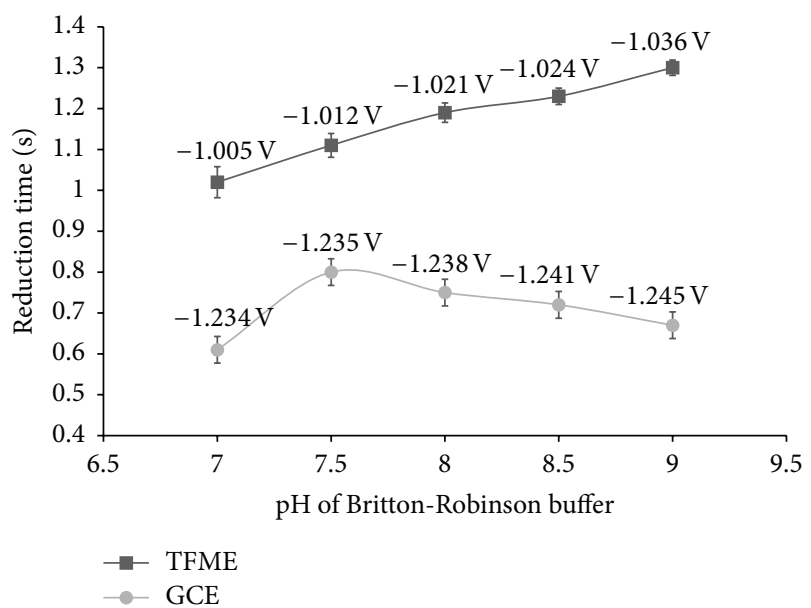

FIGURE 2: Effect of $\mathrm{pH}$ of BR buffer on the reduction time (s) and reduction peak potential (V) on TFME and GCE. Concentration of imidacloprid $10 \mathrm{mg} / \mathrm{L}$, mean $\pm 2 \mathrm{SD}, n=5$.

reduction wave on TFME from -0.97 to $-1.04 \mathrm{~V}$ and on GCE from -1.18 to $-1.28 \mathrm{~V}$. In reversible potential scan, the absence of oxidation peak indicated that the electrode reactions are irreversible. Among the studied electrolytes, the highest sensitivity, well-defined reduction peak with good reproducibility was achieved using BR buffer, so this buffer was chosen as a supporting electrolyte. In order to choose optimal $\mathrm{pH}$ value of the BR buffer, chronopotentiograms of fixed concentrations of imidacloprid $(1,10$, and $20 \mathrm{mg} / \mathrm{L}$ ), with varying $\mathrm{pH}$ value of the buffer in the range from 2 to 10 , were recorded, while other parameters of the analysis were kept constant. In general, higher sensitivity towards imidacloprid electroreduction was achieved on TFME in comparison to GCE.

In the $\mathrm{pH}$ range from 2 to 6 signal of imidacloprid was not observed on both working electrodes, since the ending potential was not reached due to a blockage of the electrode. In alkaline buffers $(\mathrm{pH}>9)$ sufficient sensitivity was not achieved. Thus, a well-defined reduction wave of imidacloprid was obtained in narrow $\mathrm{pH}$ limit of the BR buffer from 7 to 9 (Figure 2). Within this $\mathrm{pH}$ range, imidacloprid signal on TFME slightly increased with $\mathrm{pH}$ increase, while on GCE reached maximum at $\mathrm{pH} 7.5$ and then slightly decreased. In addition, on both working electrodes, the reduction peak potential shifted negatively with increasing of $\mathrm{pH}$ of $\mathrm{BR}$ buffer (Figure 2). As the most appropriate supporting electrolyte for TFME the BR buffer at $\mathrm{pH} 9.0$ was chosen, while in the case of GCE pH 7.5 was more appropriate. Reproducibility of the imidacloprid analytical signals was very good (TFME, $\mathrm{RSD}=1.39 \%, n=5 ; \mathrm{GCE}, \mathrm{RSD}=2.08 \%, n=5$ ). Chronopotentiograms recorded in BR buffers containing $10 \mathrm{mg} / \mathrm{L}$ of imidacloprid at $\mathrm{pH} 9$ and $\mathrm{pH} 7.5$ on TFME and GCE, respectively, are shown in Figure 3.

3.2. Influence of the Initial Potential. Influence of the initial potential on insecticide reduction time using TFME was investigated in the solution containing $1 \mathrm{mg} / \mathrm{L}$ of imidacloprid and by applying reduction current of $-5.0 \mu \mathrm{A}$. Well 


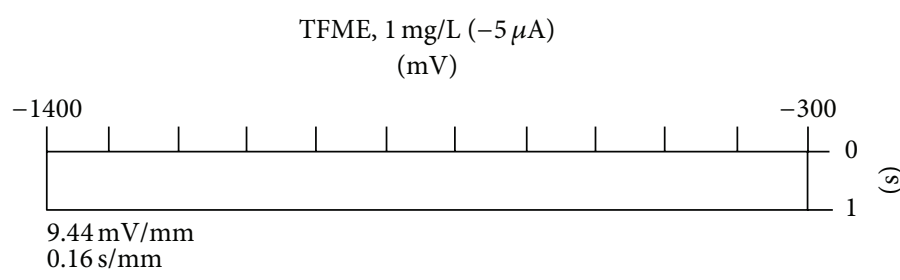

(a)

GCE, $10 \mathrm{mg} / \mathrm{L}(-8.9 \mu \mathrm{A})$

$(\mathrm{mV})$

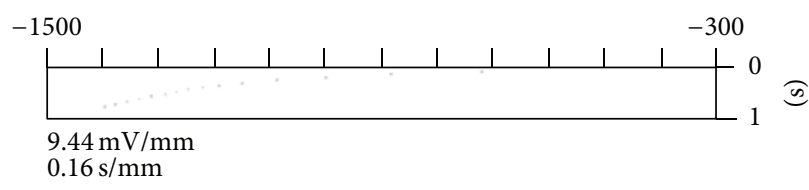

(c)
TFME, $1 \mathrm{mg} / \mathrm{L}(-5 \mu \mathrm{A})$

$(\mathrm{mV})$

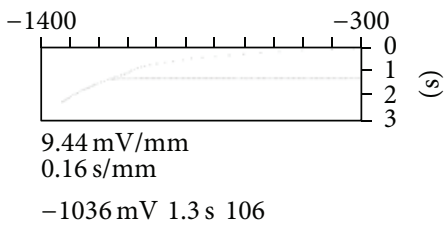

(b)

GCE, $10 \mathrm{mg} / \mathrm{L}(-8.9 \mu \mathrm{A})$

$(\mathrm{mV})$

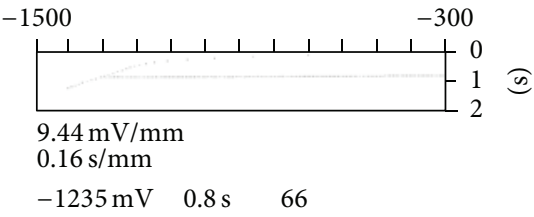

(d)

Figure 3: Chronopotentiograms of imidacloprid on a TFME ((a) $c=0 \mathrm{mg} / \mathrm{L} ;(\mathrm{b}) c=1 \mathrm{mg} / \mathrm{L}, i=-5 \mu \mathrm{A})$ and on GCE $((\mathrm{c}) c=0 \mathrm{mg} / \mathrm{L}$; (d) $c=$ $10 \mathrm{mg} / \mathrm{L}, i=-8.9 \mu \mathrm{A})$.

defined signals occurred in the range of initial potential from $-0.12 \mathrm{~V}$ to $-0.85 \mathrm{~V}$. Values of the initial potential higher than $-0.09 \mathrm{~V}$ led to permanent damage of mercury film, while at more negative values the analyte could not be detected. When GCE was used, investigated concentration of imidacloprid was $10 \mathrm{mg} / \mathrm{L}$ and reduction current of $-8.9 \mu \mathrm{A}$. Initial potentials more positive than $-0.25 \mathrm{~V}$ provided outstretched chronopotentiograms. Well defined peaks of imidacloprid were detected in the range of initial potential from -0.25 to $-1.00 \mathrm{~V}$. According to the height and reproducibility of imidacloprid signal, values of initial potential chosen as suitable were on $-0.18 \mathrm{~V}(\mathrm{RSD}=0.02 \%, n=5)$ and $-0.25 \mathrm{~V}$ (RSD $=2.55 \%, n=5)$ for TFME and GCE, respectively. Applied values of the final potentials were for TFME $-1.35 \mathrm{~V}$ and for GCE $-1.42 \mathrm{~V}$. By applying more negative values than accepted, outstretching of chronopotentiograms occurred, and analysis was significantly prolonged.

3.3. Influence of the Reduction Current. In chronopotentiometric analysis, the reduction current is one of the most important parameters of the analysis; it influences the height and sharpness of the analytical signal. Studied ranges of reduction current on TFME for solutions containing 1 and $5 \mathrm{mg} / \mathrm{L}$ were from -2.3 to $-10.1 \mu \mathrm{A}$ and from -3.2 to $-27.6 \mu \mathrm{A}$, respectively. The reduction time of imidacloprid exponentially decreased with more negative values of reduction current for both investigated concentrations of imidacloprid $\left(c=1 \mathrm{mg} / \mathrm{L}: \tau_{\text {red }}=4.8384 \mathrm{e}^{0.2918 I}, r=0.9985 ; c=5 \mathrm{mg} / \mathrm{L}:\right.$ $\left.\tau_{\text {red }}=2.2576 \mathrm{e}^{0.1182 I}, r=0.9974\right)$. Similar correlations were observed on GCE for studied concentrations of $10 \mathrm{mg} / \mathrm{L}$ $\left(\tau_{\text {red }}=6.3775 \mathrm{e}^{0.2061 I}, r=0.9973\right)$ and $30 \mathrm{mg} / \mathrm{L}\left(\tau_{\text {red }}=\right.$ $\left.6.4065 \mathrm{e}^{0.1068 I}, r=0.9988\right)$, with ranges of reduction current from -6.6 to $-10.4 \mu \mathrm{A}$ and from -8.8 to $-31.8 \mu \mathrm{A}$, respectively. Based on criterion of rectilinear sequence of the dependence $I \cdot \tau_{\mathrm{red}}{ }^{1 / 2}=f(I)$, the appropriate intervals of reduction current that should be applied for investigated concentrations on TFME ( 1 and $5 \mathrm{mg} / \mathrm{L}$ ) are from -3.8 to $-9.4 \mu \mathrm{A}$ and from -10.1 to $-27.6 \mu \mathrm{A}$, respectively. On GCE, optimal intervals of reduction current for concentrations of 10 and $30 \mathrm{mg} / \mathrm{L}$ are from -6.6 to $-9.7 \mu \mathrm{A}$ and from -14.0 to $-26 \mu \mathrm{A}$. Generally, for detecting lower concentrations lower absolute values of the current are required and vice versa. Thus, the appropriate value of reduction current that should be applied in the analysis should be selected from the above mentioned ranges, depending on the working electrode and studied concentration. Given the wide range of the current at which the signal of imidacloprid was obtained, the reduction potential did not vary significantly. Imidacloprid reduction wave on TFME was appeared at a potential range from $-0.97 \mathrm{~V}$ to $-1.12 \mathrm{~V}(\mathrm{RSD}=4.20 \%, n=45)$, while somewhat lower deviation of reduction potential was observed on GCE from -1.20 to $-1.28 \mathrm{~V}(\mathrm{RSD}=1.59 \%, n=45)$.

\subsection{Validation of Method}

3.4.1. Linearity. Linearity was estimated by analysing standard solutions containing imidacloprid in the range from 0.8 to $30.0 \mathrm{mg} / \mathrm{L}$ on TFME and on GCE from 7.0 to $70.0 \mathrm{mg} / \mathrm{L}$. In chronopotentiometry characteristic dependence of the transition time versus concentrations implies polynomial characteristic, but analytical methodologies tend to perform quantification in linear range. Accordingly, three individual concentrations ranges were considered in order to cover broader range of imidacloprid contents. For every studied concentration range different reduction current was applied and experiments were performed in five replicates. Calibration plots, standard deviations of the intercept $\left(\mathrm{S}_{a}\right)$, and slope $\left(\mathrm{S}_{b}\right)$ obtained by the least squares linear regression method, with applied reduction current are summarized in Table 1. Under the optimal experimental conditions, very good linear correlations were obtained for three concentration ranges on 
TABLE 1: Linear ranges for chronopotentiometric determination of imidacloprid using thin film mercury and glassy carbon electrode.

\begin{tabular}{lccccccc}
\hline Electrode & Concentration range $[\mathrm{mg} / \mathrm{L}]$ & Reduction current $[\mu \mathrm{A}]$ & Slope & Intercept & $\mathrm{S}_{b}{ }^{\mathrm{a}}$ & $\mathrm{S}_{a}{ }^{\mathrm{b}}$ & $r$ \\
\hline \multirow{3}{*}{ Thin film Mercury Electrode } & $0.8-2.0$ & -3.8 & 0.257 & 0.898 & 0.0187 & 0.0131 & 0.9989 \\
& $2.0-10.0$ & -6.2 & 0.132 & 0.390 & 0.0020 & 0.0195 & 0.9975 \\
& $10.0-30.0$ & -16.8 & 0.086 & -0.280 & 0.0022 & 0.0123 & 0.9980 \\
\hline \multirow{3}{*}{ Glassy Carbon Electrode } & $7.0-15.0$ & -6.6 & 0.046 & 0.329 & 0.0031 & 0.0129 & 0.9976 \\
& $10.0-40.0$ & -14.0 & 0.032 & 0.038 & 0.0007 & 0.0012 & 0.9987 \\
& $40.0-70.0$ & -18.4 & 0.051 & -0.730 & 0.0002 & 0.0220 & 0.9986 \\
\hline
\end{tabular}

${ }^{a} S_{b}$ represents the standard deviation of the slope in $s \cdot L / m g, n=5$.

${ }^{\mathrm{b}} \mathrm{S}_{a}$ represents the standard deviation of the intercept in $\mathrm{s}, n=5$.

both working electrodes, with correlation coefficients in the range from 0.9975 to 0.9989 . As reduction current significantly influences the method sensitivity, different applied reduction current was resulting in different slopes of defined calibration curves.

3.4.2. Limit of Detection and Limit of Quantification. The limit of detection (LOD) and limit of quantification (LOQ) values were calculated by the following formulas: $\mathrm{LOD}=$ $3.3 \mathrm{~S}_{a} / b$ and LOQ $=10 \mathrm{~S}_{a} / b$ [50], where $S_{a}$ is the standard deviation of the intercept, and $b$ is the slope of the calibration curve, both defined for the LOD concentration range (0.8$2.0 \mathrm{mg} / \mathrm{L}$ by using TFME, and 7.0-15.0 mg/L by using GCE). The calculated values of LOD were $0.17 \mathrm{mg} / \mathrm{L}$ for TFME and $0.92 \mathrm{mg} / \mathrm{L}$ for GCE and of LOQ were $0.51 \mathrm{mg} / \mathrm{L}$ for TFME and $2.80 \mathrm{mg} / \mathrm{L}$ for GCE. In comparison to pulse polarographic and voltammetric techniques, chronopotentiometric method proposed in this work showed lower sensitivity towards imidacloprid determination (Table 2). However, it should be considered that application of previously mentioned techniques is limited to use of HMDE. Numerous disadvantages that are related to these electrodes can be overcome by using mercury film electrodes. They can be of fairly small size, provide larger surface-to-volume ratio, are mechanically more stable than mercury drops, and require only minute quantities of mercury and the possibility for in situ analysis [51]. Multitude of modified GCEs also contributed to increase of sensitivity towards imidacloprid determination, but these electrodes require long and complicated preparation procedures, and some of them $(\beta-\mathrm{CDP} / \mathrm{rGO} / \mathrm{GCE}$ and $\mathrm{PCz} / \mathrm{CRGO} / \mathrm{GCE})$ did not find its practical application [32, 42]. Bismuth, silver-amalgam based electrodes, CPEs, and GCEs represent also attempts to avoid the use of mercury in imidacloprid determination, but it is evident that these electrodes did not show adequate sensitivity (Table 2). From the aspect of this study, since GCE did not show respectable sensitivity, chronopotentiometry with use of TFME represents a quick and easy access in imidacloprid determination, and, with prior concentration of the sample by SPE, it shows to be more sensitive in comparison with other reported electrochemical methods (Table 2). In fact, by using the SPE method in analysis of real samples, as it was described for LC-MS/MS analysis, detection limit for thin film mercury electrode could be improved up to $0.01 \mathrm{mg} / \mathrm{L}$.
3.4.3. Precision. Precision was estimated by values of repeatability (intraday precision) and reproducibility (interday precision) for two concentrations of imidacloprid. Repeatability was determined by the value of relative standard deviation (RSD) for five replicate analyses of identically prepared standard solutions of imidacloprid within the same day. Reproducibility was determined by calculating the RSD value obtained by determining imidacloprid on five successive days. Investigated concentrations on TFME were 1 and $5 \mathrm{mg} / \mathrm{L}$, applying reduction currents of -5.0 and $-10.1 \mu \mathrm{A}$, respectively. On GCE concentrations of 10 and $30 \mathrm{mg} / \mathrm{L}$ were investigated, while applied reduction currents were -8.9 and $-16.7 \mu \mathrm{A}$, respectively. In all experiments related to estimation of precision gained values of RSD were less than $3.73 \%$, indicating good precision of the presented method independently of the working electrode applied.

3.4.4. Selectivity. The selectivity of the presented method was tested by addition of various inorganic ions and two reducible herbicides metribuzin and metamitron to the solution containing fixed concentration of imidacloprid. Selected inorganic ions $\left(\mathrm{K}^{+}, \mathrm{Na}^{+}, \mathrm{Ca}^{2+}, \mathrm{Mg}^{2+}, \mathrm{SO}_{4}{ }^{2-}, \mathrm{Cl}^{-}\right.$, $\mathrm{HCO}_{3}{ }^{-}, \mathrm{NO}_{3}{ }^{-}$, and $\mathrm{Fe}^{2+}$ ) which could be present in environmental water samples were added in the concentration ratios (imidacloprid:interferent) of $1: 0.1,1: 1,1: 10$, and $1: 50$. The influence of inorganic ions on analytical signal of imidacloprid was tested on both working electrodes, while the influence of herbicides was investigated using TFME. Considering the precision of the method, a compound was considered to interfere seriously if it provoked the change of imidacloprid signal more than 5\%. Tested concentrations of imidacloprid on TFME and GCE were $1 \mathrm{mg} / \mathrm{L}$ and $10 \mathrm{mg} / \mathrm{L}$, respectively. The majority of tested ions $\left(\mathrm{K}^{+}\right.$, $\mathrm{NO}_{3}{ }^{-}, \mathrm{Cl}^{-}, \mathrm{HCO}_{3}{ }^{-}$, and $\mathrm{SO}_{4}{ }^{2-}$ ) in 50 -fold excess provoked minor decrease of analytical signal, while $\mathrm{Ca}^{2+}, \mathrm{Mg}^{2+}$, and $\mathrm{Na}^{+}$slightly increased imidacloprid signal, with maximum change of $4.96 \%$. Concerning $\mathrm{Fe}^{2+}$ ions, its presence at concentrations less than $10 \mathrm{mg} / \mathrm{L}$ led to signal change within the $5 \%$ limit, while higher concentrations slightly decreased the analytical signal. This phenomenon could be attributed to a $\mathrm{Fe}^{2+}$ reduction peak [52], which interfered with imidacloprid determination. This fact could somewhat reduce the selectivity of the method, but when considering the possibility of using developed method for determination of 
TABLE 2: Comparison of limit of detection (LOD) of the presented chronopotentiometric method with previously reported electrochemical methods for imidacloprid determination.

\begin{tabular}{|c|c|c|c|}
\hline $\mathrm{LOD}[\mathrm{mg} / \mathrm{L}]$ & Technique & Electrode & Reference \\
\hline 0.0030 & Differential pulse polarography & HMDE & [33] \\
\hline 0.0041 & Square wave adsorptive stripping voltammetry & HMDE & [34] \\
\hline 0.0051 & Differential pulse voltammetry & $\beta-\mathrm{CDP} / \mathrm{rGO} / \mathrm{GCE}$ & {$[42]$} \\
\hline 0.0128 & Linear sweep voltammetry & Prussian blue/MWNT/GCE & {$[40]$} \\
\hline 0.0134 & Chronopotentiometry with SPE & TFME & This study \\
\hline 0.0256 & Cyclic voltammetry & $\beta-\mathrm{CDP} / \mathrm{rGO} / \mathrm{GCE}$ & {$[42]$} \\
\hline 0.0563 & Cyclic voltammetry & $\mathrm{PCz} / \mathrm{CRGO} / \mathrm{GCE}$ & {$[32]$} \\
\hline 0.0640 & Differential pulse voltammetry & $\mathrm{nAgn}_{\mathrm{f}} / \mathrm{nTiO}_{2} \mathrm{n}_{\mathrm{f}} / \mathrm{GCE}$ & [41] \\
\hline 0.0716 & Differential pulse voltammetry & $\mathrm{CuPc} / \mathrm{CCE}$ & [44] \\
\hline 0.1023 & Linear sweep voltammetry & Imprinted PoPD-RGO/GCE & [43] \\
\hline 0.1125 & Differential pulse voltammetry & $\mathrm{PCz} / \mathrm{CRGO} / \mathrm{GCE}$ & {$[32]$} \\
\hline 0.1611 & Cyclic voltammetry & $\mathrm{nAgn}_{\mathrm{f}} / \mathrm{nTiO}_{2} \mathrm{n}_{\mathrm{f}} / \mathrm{GCE}$ & {$[41]$} \\
\hline 0.1682 & Chronopotentiometry & TFME & This study \\
\hline 0.2378 & Amperometry & $\mathrm{nAgn}_{\mathrm{f}} / \mathrm{nTiO}_{2} \mathrm{n}_{\mathrm{f}} / \mathrm{GCE}$ & [41] \\
\hline 0.2700 & Square wave voltammetry & $\mathrm{Hg}(\mathrm{Ag}) \mathrm{FE}$ & [39] \\
\hline 0.5200 & Differential pulse voltammetry & $\mathrm{CPE}$ & [37] \\
\hline 0.7300 & Differential pulse voltammetry & $\mathrm{BiFE}$ & {$[38]$} \\
\hline 0.9254 & Chronopotentiometry & GCE & This study \\
\hline 7.7000 & Cyclic voltammetry & GCE & [35] \\
\hline
\end{tabular}

HMDE: hanging mercury drop electrode; $\beta$-CDP/rGO/GCE: $\beta$-cyclodextrin polymer/functionalized reduced-graphene oxide/modified GCE; TFME: thin film mercury electrode; Prussian blue/MWNT/GCE: Prussian blue multiwalled carbon nanotubes modified GCE; PCz/CRGO/GCE: poly(carbazole)/chemically reduced graphene oxide modified GCE; $\mathrm{Hg}(\mathrm{Ag}) \mathrm{FE}$ : silver-amalgam film electrode; $\mathrm{nAgn}_{\mathrm{f}} / \mathrm{nTiO}_{2} \mathrm{n}_{\mathrm{f}} / \mathrm{GCE}$ : nanosilver Nafion/nano-TiO $\mathrm{Nafion}_{2}$ modified glassy carbon electrode; CuPc/CCE: copper(II) phthalocyanine modified carbon ceramic electrode; imprinted PoPD-RGO/GCE: imprinted poly(ophenylenediamine) membranes/reduced graphene oxide modified GCE; CPE: carbon paste electrode; BiFE: bismuth film electrode; GCE: glassy carbon electrode.

imidacloprid in drinking water, where $\mathrm{Fe}^{2+}$ ion is present in lower concentrations $(0.7 \mathrm{mg} / \mathrm{L})$ [53], the interference of this ion could be excluded. Caution should be made in the direct implementation of the developed method to groundwater samples, where increased concentration of mentioned ion is expected. In that case, elimination of $\mathrm{Fe}^{2+}$ ions is necessary using cationic cartridges. As concerned for the presence of herbicides, 10 -fold excess concentrations of metribuzin and metamitron and 50-fold excess concentration of metamitron provoked minor increase of imidacloprid analytical signal (less than 5\%). In the case of 50 -fold excess of metribuzin concentration, the signal change was slightly more (6.2\%).

3.4.5. Accuracy. Estimation of proposed chronopotentiometric method accuracy was based on means of analyses of imidacloprid standard solutions. Supporting electrolyte spiked with known amount of imidacloprid ( 1 and $5 \mathrm{mg} / \mathrm{dm}^{3}$ ) was analysed under optimized chronopotentiometric procedure.

Recovery test was performed in three replicates for both examined concentrations of insecticide. The percentage analytical recovery values were calculated by comparing concentrations determined from the spiked supporting electrolyte with actual added concentrations of imidacloprid. Good values of the mean recoveries of $97.3 \%$ and $98.1 \%$, for $1 \mathrm{mg} / \mathrm{dm}^{3}$ and $5 \mathrm{mg} / \mathrm{dm}^{3}$ of imidacloprid, respectively, confirmed the accuracy of the proposed method and offered the promising evidence that the developed method could be used in the analysis of real samples.
For additional check of the accuracy of the developed method, LC-MS/MS parallel analyses of river water samples were done. Obtained results are given in Section 3.5.2.

3.4.6. Robustness. The robustness of the developed method was evaluated by investigating the effect of small variations in $\mathrm{pH}$ value of supporting electrolyte $( \pm 0.2)$, the initial potential $( \pm 0.05 \mathrm{~V})$, and reduction current $(-8.2 \pm 0.3 \mu \mathrm{A})$ on the recovery of analyte. Recoveries for imidacloprid $(5 \mathrm{mg} / \mathrm{L})$ under all variable conditions were in the range of 97.1$99.4 \%$. Constancy of the transition time with deliberated small changes in the experimental parameters indicated a very good robustness of the proposed method.

\subsection{Analytical Applications}

3.5.1. Application to Commercial Formulations. In order to investigate the validity of the presented chronopotentiometric method, commercial pesticide formulations containing imidacloprid as active component were analysed. Considering the fact that no extraction steps were performed prior to analysis, except the appropriate dilution steps, no interferences were observed during the analysis. When GCE was used in the analysis of liquid formulations, due to presence of various additives that improve the formulation properties, fouling of the glassy carbon surface occurred, and gained signal of the analyte was not reproducible. Thus, between two analyses it was necessary to perform electrochemical cleaning 
TABLE 3: Results obtained for the analysis of commercial formulations by the proposed chronopotentiometric method.

\begin{tabular}{|c|c|c|c|}
\hline \multirow{2}{*}{ Commercial pesticide formulation } & \multirow{2}{*}{$\begin{array}{l}\text { Imidacloprid content claimed by } \\
\text { the manufacturer }\end{array}$} & \multicolumn{2}{|c|}{ Determined by the proposed chronopotentiometric method } \\
\hline & & TFME & GCE \\
\hline & \multicolumn{3}{|c|}{ Imidacloprid content $[\mathrm{g} / \mathrm{L}]$} \\
\hline Prestige 290 FS & 140.00 & $144.17 \pm 1.60(102.98)^{\mathrm{a}}$ & $134.27 \pm 2.52(95.91)$ \\
\hline Confidor 200 SL & 200.00 & $199.71 \pm 1.59(99.86)$ & $197.02 \pm 1.39(98.51)$ \\
\hline Kohinor 200 SL & 200.00 & $202.02 \pm 0.82(101.01)$ & $203.33 \pm 1.35(101.67)$ \\
\hline \multirow[t]{2}{*}{ Gat Go 20 OD } & 200.00 & $204.22 \pm 1.98(102.11)$ & $196.46 \pm 0.72(98.23)$ \\
\hline & \multicolumn{3}{|c|}{ Imidacloprid content $[\mathrm{g} / \mathrm{kg}]$} \\
\hline Confidor $70 \mathrm{WG}$ & 700.00 & $697.98 \pm 2.07(99.71)$ & $685.72 \pm 1.19(97.96)$ \\
\hline Imidor $70 \mathrm{WS}$ & 700.00 & $708.42 \pm 1.29(101.20)$ & $712.19 \pm 1.10(101.74)$ \\
\hline
\end{tabular}

${ }^{\mathrm{a}}$ Mean value $\pm \operatorname{RSD}($ recovery, $\%), n=3$.

TABLE 4: Results obtained for the analysis of spiked river water samples by the proposed chronopotentiometric method and reference LCMS/MS method.

\begin{tabular}{|c|c|c|c|c|c|}
\hline \multirow{2}{*}{ Sample } & \multirow{2}{*}{ Added $[\mathrm{mg} / \mathrm{L}]$} & \multicolumn{2}{|c|}{ Proposed chronopotentiometric method } & \multicolumn{2}{|c|}{ LC-MS/MS method } \\
\hline & & Found [mg/L] & Recovery [\%] & Found [mg/L] & Recovery [\%] \\
\hline 1 & 1.00 & $0.98 \pm 1.64^{\mathrm{a}}$ & 97.94 & $1.03 \pm 0.32^{\mathrm{a}}$ & 103.20 \\
\hline 2 & 1.00 & $0.98 \pm 2.56$ & 97.95 & $0.96 \pm 6.78$ & 95.92 \\
\hline 3 & 1.00 & $0.94 \pm 0.79$ & 93.64 & $0.99 \pm 2.00$ & 97.87 \\
\hline 4 & 1.00 & $0.96 \pm 2.04$ & 96.26 & $0.94 \pm 1.96$ & 93.39 \\
\hline 5 & 1.00 & $0.95 \pm 0.64$ & 95.19 & $1.02 \pm 4.50$ & 101.77 \\
\hline
\end{tabular}

${ }^{\mathrm{a}}$ Mean value $\pm \mathrm{RSD}, n=3$.

of the glassy carbon surface. The procedure consisted of ten in situ consecutive cycles of potential alternation from $-0.25 \mathrm{~V}$ to $-1.42 \mathrm{~V}$, by the current that was applied regularly for the analysis, which enables that every analysis could be performed on freshly activated surface [54]. All experiments were performed using three replicates, and imidacloprid was quantified by the standard addition method. Obtained results are presented in Table 3 . Good correlation between amounts determined and declared or added, as well as low values of RSD reflect the high accuracy and precision, indicating that presented chronopotentiometric method can be used as a routine tool for control of imidacloprid content in commercial pesticide formulations, without interferences from inactive ingredients.

3.5.2. Application to River Water Samples. Due to its high sensitivity, the present method using TFME was applied for quantification of imidacloprid content in five river water samples. Experiments were performed using three replicates, and imidacloprid content was determined by the standard addition method. By direct analysis, river water samples did not show any measurable quantities of the analyte, so they were spiked with the same concentration of the imidacloprid $(1 \mathrm{mg} / \mathrm{L})$. Moreover, the chronopotentiograms profile excluded the presence of interfering electroactive compounds in the analysed solution. Obtained results with RSD and recovery values are presented in Table 4. A parallel analysis of river water samples by LC-MS/MS method was done for additional accuracy check. According to the results from Table 4, obtained recovery values for presented chronopotentiometric method were between 93.64 and $97.95 \%$, which are acceptable for studied concentration [55]. High reproducibility of the proposed method was indicated by the maximum RSD value of $2.56 \%$. Moreover, the results of the proposed method were comparable to those obtained from the LC-MS/MS method with no significant difference between the two methods (paired $t$-test at the 95\% confidence level gave $\left|t_{\text {calculated }}\right|=$ $1.28<t_{\text {critical }}=2.78$, with 4 degrees of freedom). Based on obtained results, it is obvious that the presented method provides a good alternative for imidacloprid quantification in environmental samples with adequate sample preparation.

\section{Conclusions}

Chronopotentiometry in combination with TFME and GCE was used for the first time to develop a simple, rapid, and cheap electrochemical method for imidacloprid determination. During imidacloprid reduction, one well defined reductive peak of analyte appeared at both electrodes. The effects of the supporting electrolyte, $\mathrm{pH}$, initial and final potential, and reduction current on the analytical signal of imidacloprid was investigated. In addition, parameters related to linearity and precision were also estimated. Obtained LOD values are comparable to values reported in the literature for other electrochemical methods. Linearity and precision of the method were adequate, and correlation coefficients were higher than 0.9975 , while precision gained values of RSD were up to $3.73 \%$. High recoveries of spiked samples confirmed the accuracy of the method. The method proved as selective, since the majority of possible interferents did not 
influence the analytical signal of the analyte. The validity of the method was confirmed by direct analysis of commercial formulation containing imidacloprid with no significant differences between declared values by manufacturer and values found by the presented chronopotentiometric method. Due to higher sensitivity, the method using TFME was also applied on spiked river water samples, and the results were in good agreements with those obtained by reference LCMS/MS method. In addition, TFME represents a suitable alternative to a HMDE, due to its advantages, which include stability of thin film, minimal consumption of mercury, easy preparation and maintenance procedure, and suitability for on-site analysis. Thus, simplicity, rapidity, and low cost are the main characteristics that distinguished the presented method from previously reported electrochemical methods for imidacloprid determination. Moreover, simple preparation of working electrode and short analysis time of real samples are clear advantages of the presented method. Hence, this method can undoubtedly serve as an alternative to complicated chromatographic techniques for routine imidacloprid determination in environmental water samples.

\section{Conflict of Interests}

The authors declare that there is no conflict of interests regarding the publication of this paper.

\section{Acknowledgments}

The authors appreciate the funding from the Ministry of Education and Science of the Republic of Serbia (Grant III 46009) for supporting this study.

\section{References}

[1] M. Meissle, P. Mouron, T. Musa et al., "Pests, pesticide use and alternative options in European maize production: current status and future prospects," Journal of Applied Entomology, vol. 134, no. 5, pp. 357-375, 2010.

[2] C. D. Osteen and J. Fernandez-Cornejo, "Economic and policy issues of U.S. agricultural pesticide use trends," Pest Management Science, vol. 69, no. 9, pp. 1001-1025, 2013.

[3] P. Jeschke and R. Nauen, "Neonicotinoid insecticides," in Insect Control, Biological and Synthetic Agents, L. J. Gilbert and S. S. Gill, Eds., pp. 61-114, Elsevier, New York, NY, USA, 2010.

[4] A. Zhang, H. Kaiser, P. Maienfisch, and J. E. Casida, "Insect nicotinic acetylcholine receptor: conserved neonicotinoid specificity of $\left[{ }^{3} \mathrm{H}\right]$ imidacloprid binding site," Journal of Neurochemistry, vol. 75, no. 3, pp. 1294-1303, 2000.

[5] M. Y. Liu and J. E. Casida, "High affinity binding of $\left[{ }^{3} \mathrm{H}\right] \mathrm{imi}-$ dacloprid in the insect acetylcholine receptor," Pesticide Biochemistry and Physiology, vol. 46, no. 1, pp. 40-46, 1993.

[6] F. Sanchez-Bayo and K. Goka, "Pesticide residues and bees-a risk assessment," PLoS ONE, vol. 9, no. 4, Article ID e94482, pp. 1-16, 2014.

[7] C. Lu, K. M. Warchol, and R. A. Callahan, "In situ replication of honey bee colony collapse disorder," Bulletin of Insectology, vol. 65, no. 1, pp. 99-106, 2012.

[8] A. Tapparo, D. Marton, C. Giorio et al., "Assessment of the environmental exposure of honeybees to particulate matter containing neonicotinoid insecticides coming from corn coated seeds," Environmental Science and Technology, vol. 46, no. 5, pp. 2592-2599, 2012.

[9] P. R. Whitehorn, S. O’Connor, F. L. Wackers, and D. Goulson, "Neonicotinoid pesticide reduces bumble bee colony growth and queen production," Science, vol. 336, no. 6079, pp. 351-352, 2012.

[10] C. A. Morrissey, P. Mineau, J. H. Devries et al., "Neonicotinoid contamination of global surface waters and associated risk to aquatic invertebrates: a review," Environment International, vol. 74, pp. 291-303, 2015.

[11] T. Tišler, A. Jemec, B. Mozetič, and P. Trebše, "Hazard identification of imidacloprid to aquatic environment," Chemosphere, vol. 76, no. 7, pp. 907-914, 2009.

[12] S. J. Stoughton, K. Liber, J. Culp, and A. Cessna, "Acute and chronic toxicity of imidacloprid to the aquatic invertebrates Chironomus tentans and Hyalella azteca under constant- and pulse-exposure conditions," Archives of Environmental Contamination and Toxicology, vol. 54, no. 4, pp. 662-673, 2008.

[13] A. C. Alexander, J. M. Culp, K. Liber, and A. J. Cessna, "Effects of insecticide exposure on feeding inhibition in mayflies and oligochaetes," Environmental Toxicology and Chemistry, vol. 26, no. 8, pp. 1726-1732, 2007.

[14] F. Sánchez-Bayo and K. Goka, "Ecological effects of the insecticide imidacloprid and a pollutant from antidandruff shampoo in experimental rice fields," Environmental Toxicology and Chemistry, vol. 25, no. 6, pp. 1677-1687, 2006.

[15] E. Benton, J. Grant, T. Mueller, R. Webster, and R. Nichols, "Consequences of imidacloprid treatments for hemlock woolly adelgid on stream water quality in the southern Appalachians," Forest Ecology and Management, vol. 360, pp. 152-158, 2016.

[16] A. Lopez-Antia, M. E. Ortiz-Santaliestra, F. Mougeot, and R. Mateo, "Imidacloprid-treated seed ingestion has lethal effect on adult partridges and reduces both breeding investment and offspring immunity," Environmental Research, vol. 136, pp. 97107, 2015.

[17] T. R. Roberts and D. H. Hutson, Metabolic Pathways of Agrochemicals, Part 2: Insecticides and Fungicides, The Royal Society of Chemistry, Cambridge, UK, 1999.

[18] D. P. Weston, D. Chen, and M. J. Lydy, "Stormwater-related transport of the insecticides bifenthrin, fipronil, imidacloprid, and chlorpyrifos into a tidal wetland, San Francisco Bay, California," Science of The Total Environment, vol. 527-528, pp. 18-25, 2015.

[19] M. P. Ensminger, R. Budd, K. C. Kelley, and K. S. Goh, "Pesticide occurrence and aquatic benchmark exceedances in urban surface waters and sediments in three urban areas of California, USA, 2008-2011," Environmental Monitoring and Assessment, vol. 185, no. 5, pp. 3697-3710, 2013.

[20] S. A. Baig, N. A. Akhter, M. Ashfaq, M. R. Asi, and U. Ashfaq, "Imidacloprid residues in vegetables, soil and water in the southern Punjab, Pakistan," Journal of Agricultural Technology, vol. 8, no. 3, pp. 903-916, 2012.

[21] K. Starner and K. S. Goh, "Detections of the neonicotinoid insecticide imidacloprid in surface waters of three agricultural regions of California, USA, 2010-2011," Bulletin of Environmental Contamination and Toxicology, vol. 88, no. 3, pp. 316-321, 2012.

[22] M. Lamers, M. Anyusheva, N. La, V. V. Nguyen, and T. Streck, "Pesticide pollution in surface- and groundwater by paddy rice cultivation: a case study from Northern Vietnam," Clean-Soil, Air, Water, vol. 39, no. 4, pp. 356-361, 2011. 
[23] J. Kreuger, S. Graaf, J. Patring, and S. Adielsson, Pesticides in Surface Water in Areas with Open Ground and Greenhouse Horticultural Crops in Sweden 2008, Swedish University of Agricultural Sciences Division of Water Quality Menagement, 2010, http://pub.epsilon.slu.se/5413/1/kreuger_j_et_al_101014.pdf.

[24] A. Daraghmeh, A. Shraim, S. Abulhaj, R. Sansour, and J. C. Ng, "Imidacloprid residues in fruits, vegetables and water samples from Palestine," Environmental Geochemistry and Health, vol. 29, no. 1, pp. 45-50, 2007.

[25] T. C. Van Dijk, M. A. Van Staalduinen, and J. P. Van der Sluijs, "Macro-invertebrate decline in surface water polluted with imidacloprid," PLoS ONE, vol. 8, no. 5, Article ID e62374, 2013.

[26] V. Guzsvány, A. Madžgalj, P. Treběe, F. Gaál, and M. Franko, "Determination of selected neonicotinoid insecticides by liquid chromatography with thermal lens spectrometric detection," Environmental Chemistry Letters, vol. 5, no. 4, pp. 203-208, 2007.

[27] S. Seccia, P. Fidente, D. A. Barbini, and P. Morrica, "Multiresidue determination of neonicotinoid insecticide residues in drinking water by liquid chromatography with electrospray ionization mass spectrometry," Analytica Chimica Acta, vol. 553, no. 1-2, pp. 21-26, 2005.

[28] M. Martínez Galera, A. Garrido Frenich, J. L. Martínez Vidal, and P. Parrilla Vázquez, "Resolution of imidacloprid pesticide and its metabolite 6-chloronicotinic acid using cross-sections of spectrochromatograms obtained by high-performance liquid chromatography with diode-array detection," Journal of Chromatography A, vol. 799, no. 1-2, pp. 149-154, 1998.

[29] S. Baskaran, R. S. Kookana, and R. Naidu, "Determination of the insecticide imidacloprid in water and soil using highperformance liquid chromatography," Journal of Chromatography A, vol. 787, no. 1-2, pp. 271-275, 1997.

[30] F. Sánchez-Bayo and R. V. Hyne, "Detection and analysis of neonicotinoids in river waters-development of a passive sampler for three commonly used insecticides," Chemosphere, vol. 99, pp. 143-151, 2014.

[31] S. Girotti, E. Maiolini, S. Ghini, S. Eremin, and J. Mañes, "Quantification of imidacloprid in honeybees: development of a chemiluminescent Elisa," Analytical Letters, vol. 43, no. 3, pp. 466-475, 2010.

[32] W. Lei, Q. Wu, W. Si et al., "Electrochemical determination of imidacloprid using poly(carbazole)/chemically reduced graphene oxide modified glassy carbon electrode," Sensors and Actuators B: Chemical, vol. 183, pp. 102-109, 2013.

[33] A. Navalón, R. Ei-Khattabi, A. González-Casado, and J. L. Vilchez, "Differential-pulse polarographic determination of the insecticide imidacloprid in commercial formulations," Mikrochimica Acta, vol. 130, no. 4, pp. 261-265, 1999.

[34] A. Guiberteau, T. Galeano, N. Mora, P. Parrilla, and F. Salinas, "Study and determination of the pesticide imidacloprid by square wave adsorptive stripping voltammetry," Talanta, vol. 53, no. 5, pp. 943-949, 2001.

[35] V. J. Guzsvány, F. F. Gaál, L. J. Bjelica, and S. N. Ökrész, "Voltammetric determination of imidacloprid and thiamethoxam," Journal of the Serbian Chemical Society, vol. 70, no. 5, pp. 735$743,2005$.

[36] V. Guzsvány, Z. Papp, J. Zbiljić, O. Vajdle, and M. Rodić, "Bismuth modified carbon-based electrodes for the determination of selected neonicotinoid insecticides," Molecules, vol. 16, no. 6 , pp. 4451-4466, 2011.
[37] Z. Papp, I. Švancara, V. Guzsvány, K. Vytřas, and F. Gaál, "Voltammetric determination of imidacloprid insecticide in selected samples using a carbon paste electrode," Microchimica Acta, vol. 166, no. 1-2, pp. 169-175, 2009.

[38] V. Guzsvány, M. Kádár, Z. Papp, L. Bjelica, F. Gaál, and K. Tóth, "Monitoring of photocatlytic degradation of selected neonicotinoid insecticides by cathodic voltammetry with a bismuth film electrode," Electroanalysis, vol. 20, no. 3, pp. 291300, 2008.

[39] V. Guzsvány, J. Petrović, J. Krstić et al., "Renewable silveramalgam film electrode for voltammetric monitoring of solar photodegradation of imidacloprid in the presence of $\mathrm{Fe} / \mathrm{TiO}_{2}$ and $\mathrm{TiO}_{2}$ catalysts," Journal of Electroanalytical Chemistry, vol. 699, pp. 33-39, 2013.

[40] G.-D. Jin and X.-Y. Hu, "Study and determination of pesticide imidacloprid by linear sweep voltammetry at a prussian blue and MWNT modified glassy carbon electrode," Chinese Journal of Analysis Laboratory, vol. 27, no. 4, pp. 14-17, 2008.

[41] A. Kumaravel and M. Chandrasekaran, "Electrochemical determination of imidacloprid using nanosilver Nafion $/$ nanoTiO $_{2}$ Nafion composite modified glassy carbon electrode," Sensors and Actuators B: Chemical, vol. 158, no. 1, pp. 319-326, 2011.

[42] M. Chen, Y. Meng, W. Zhang, J. Zhou, J. Xie, and G. Diao, “ $\beta$ cyclodextrin polymer functionalized reduced-graphene oxide: application for electrochemical determination imidacloprid," Electrochimica Acta, vol. 108, pp. 1-9, 2013.

[43] L. Kong, X. Jiang, Y. Zeng, T. Zhou, and G. Shi, "Molecularly imprinted sensor based on electropolmerized poly(ophenylenediamine) membranes at reduced graphene oxide modified electrode for imidacloprid determination," Sensors and Actuators, B: Chemical, vol. 185, pp. 424-431, 2013.

[44] M. R. Majidi, K. Asadpour-Zeynali, M. Bamorowat, and M. Nazarpur, "Determination of Imidacloprid in tomato grown in greenhouse based on copper(II) phthalocyanine modified carbon ceramic electrode by differential pulse voltammetry," Journal of the Chinese Chemical Society, vol. 58, no. 2, pp. 207214, 2011.

[45] "Validation and Peer Review of US EPA Chemical Methods of Analysis," EPA, 2005, http://www.epa.gov/sites/production/files/ 2015-01/documents/chemmethod_validity_guide.pdf.

[46] J. Švarc-Gajić and Z. Stojanović, "Determination of histamine in cheese by chronopotentiometry on a thin film mercury electrode," Food Chemistry, vol. 124, no. 3, pp. 1172-1176, 2011.

[47] ATC, "Determination of pesticide residues in water by LCMS/MS," Method VDM 0219, Institute of Public Health, Belgrade, Serbia, 2014, http://www.zdravlje.org.rs/files/Akreditacija/01-036\%20Obim\%20akreditacije,\%20PDF,\%20vazi\%20od \%2008-05-2014.pdf.

[48] A. Đurović, Z. Stojanović, N. Grahovac et al., "Deaeration method for imidacloprid determination on glassy carbon electrode," in Proceedings of the 2nd International Congress, Food Technology, Quality and Safety, pp. 171-175, Novi Sad, Serbia, 2014.

[49] L. Janikova-Bandzuchova, R. Šelešovská, K. SchwarzováPecková, and J. Chýlková, "Sensitive voltammetric method for rapid determination of pyridine herbicide triclopyr on bare boron-doped diamond electrode," Electrochimica Acta, vol. 154, pp. 421-429, 2015.

[50] International Conference on Harmonisation (ICH), Validation of Analytical Procedures: Text and Methodology, ICH, Geneva, Switzerland, 1996, http://www.gmp-compliance.org/ guidemgr/files/Q2(R1).PDF. 
[51] A. Economou and P. R. Fielden, "Mercury film electrodes: developments, trends and potentialities for electroanalysis," Analyst, vol. 128, no. 3, pp. 205-213, 2003.

[52] A. J. Bard, R. Parsons, and J. Jordan, Standard Potentials in Aqueous Solution, Marcel Dekker, New York, NY, USA, 1985.

[53] World Health Organization, Iron in Drinking-Water Background Document for Development of WHO Guidelines for DrinkingWater Quality, vol. 2, World Health Organization, Geneva, Switzerland, 2nd edition, 1996, http://www.who.int/water _sanitation_health/dwq/chemicals/iron.pdf.

[54] J. Wang and M. S. Lin, "In situ electrochemical renewal of glassy carbon electrodes," Analytical Chemistry, vol. 60, no. 5, pp. 499502,1988

[55] A. G. González, M. Á. Herrador, and A. G. Asuero, "Intra-laboratory assessment of method accuracy (trueness and precision) by using validation standards," Talanta, vol. 82, no. 5, pp. 19951998, 2010. 

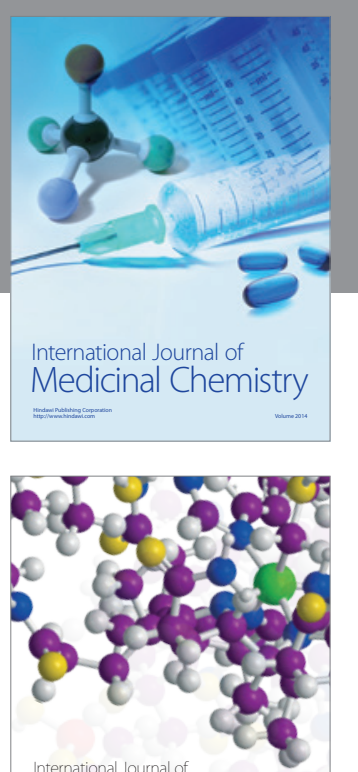

Carbohydrate Chemistry

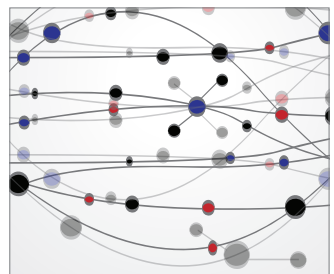

The Scientific World Journal
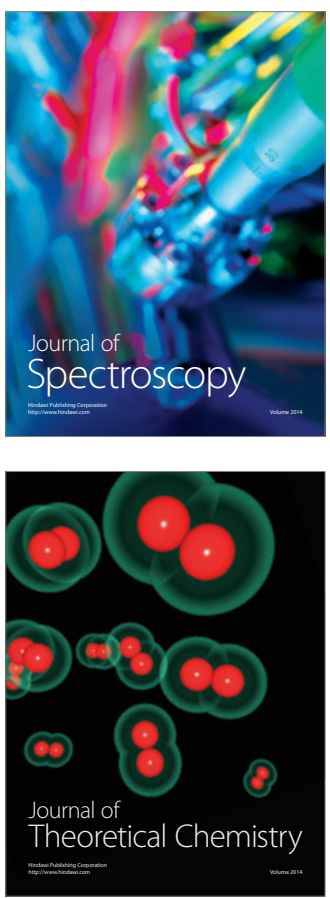
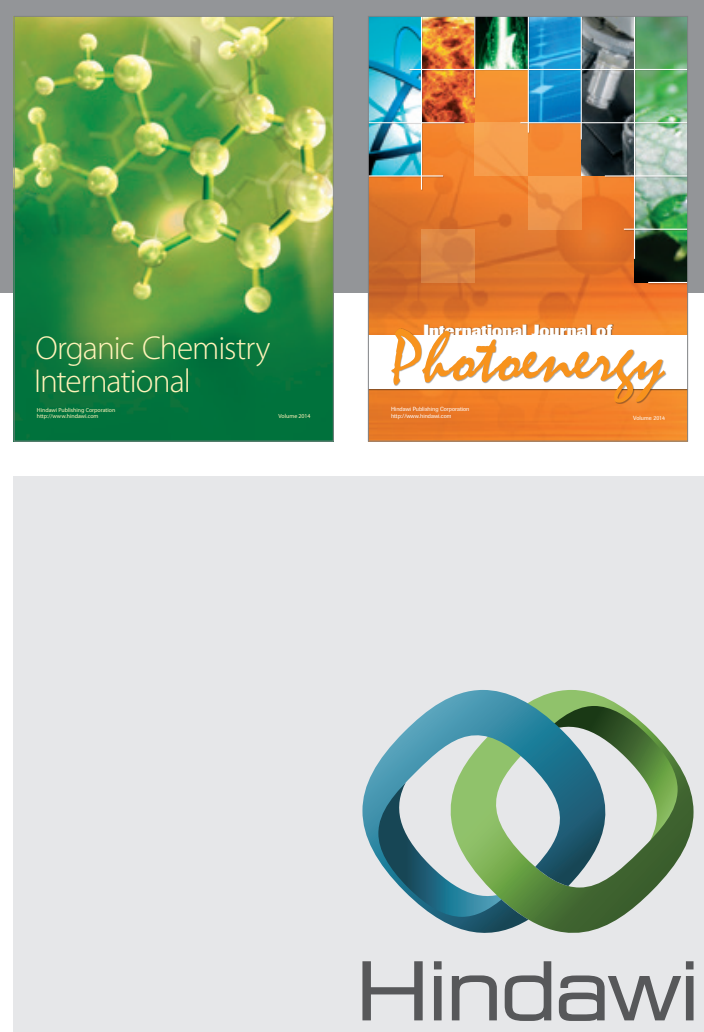

Submit your manuscripts at

http://www.hindawi.com

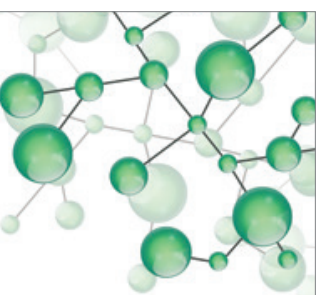

International Journal of

Inorganic Chemistry

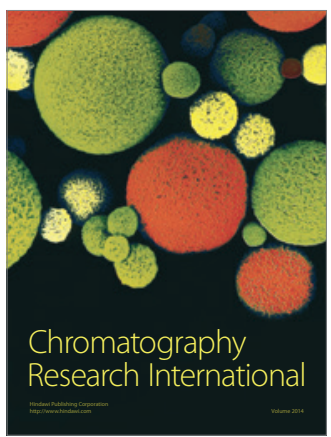

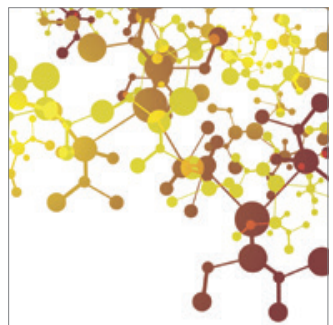

Applied Chemistry
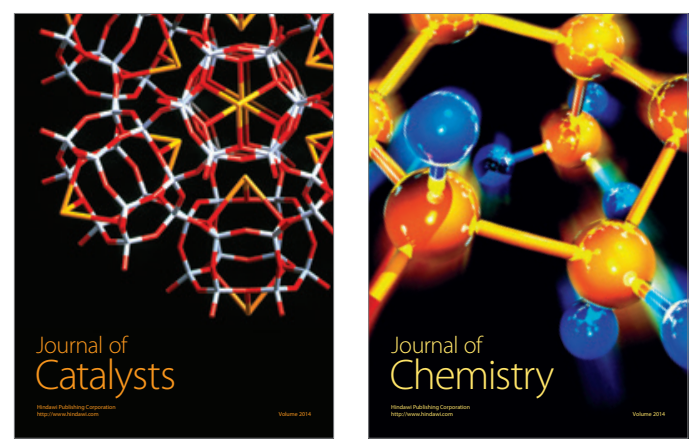
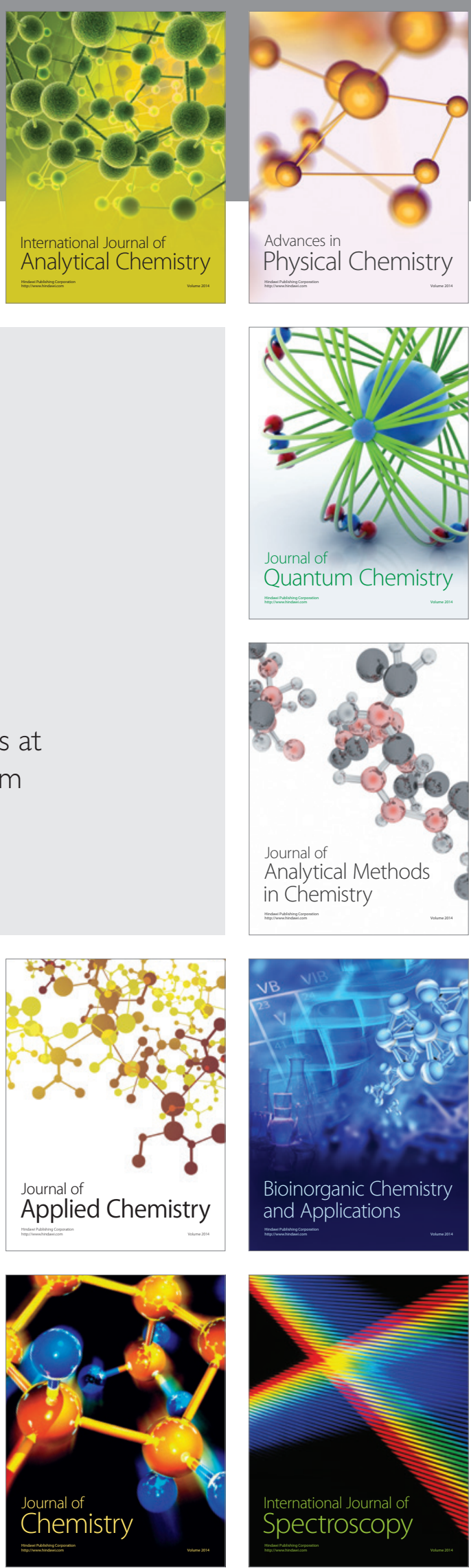